\title{
Regulation Features in Individuals with Personality Disorders and Accentuated Personality Traits Who Committed Aggressive and Violent Crimes
}

\section{ELENA S. SHEKHOVTSOVA}

Serbsky National Medical Research Center for Psychiatry and Narcology under the Ministry of Health of the Russian Federation, Moscow, Russian Federation

ORCID: https://orcid.org/0000-0003-3379-3521, e-mail: shiha.|@mail.ru

\section{VERA G. BULYGINA}

Serbsky National Medical Research Center for Psychiatry and Narcology under the Ministry of Health of the Russian Federation; Moscow State University of Psychology \& Education, Moscow, Russian Federation

ORCID: https://orcid.org/0000-0001-5584-1251, e-mail: ver210@yandex.ru

Abstract. The paper investigates individual psychological features of selfregulation in people with personality disorders and accentuated personality traits. Our goal is to specify the data on regulation disorders taking into account the nature of committed offences so as to substantiate the validity of expert conclusions, promote individualization in punishment, and build models for secondary psychological prevention. We survey 134 men including 94 individuals with personality disorders, 20 individuals with accentuated personality traits and 20 individuals without mental disorders. We use a set of methodological tools to assess the extent of self-control deficiency); the set includes J. Kagan's Matching Familiar Figures Test, situation analysis, a new questionnaire for tolerance toward uncertainty, J. Stroop's Color and Word Test, behavioral self-regulation style. We carry out statistical processing of the data with the help of descriptive statistics method, frequency analysis, an independent samples t-test, the Mann-Whitney U-test, and the Kruskal-Wallis test to compare three independent samples. We have found out that regulation disorders in people with personality disorders who committed violent crimes are associated with the ability to predict the consequences adequately and find socially acceptable ways to resolve problem situations. We show that when an individual has to deal with information shortage,contradictory information, perceptual interference or increased emotional intensity of the situationthe probability of disorders in their conscious regulation of behavior increases significantly. Accordingly, to address the tasks of penal science and practice, we consider it expedient to use the indicators identified in the course of our present research, because they can be not only predictors of behavioral dysregulation and aggressive responses, but also targets for psychological therapy.

Key words: self-regulation; personality disorders; accentuated personality traits; situation analysis; type of offence.

19.00.06 - Legal psychology (psychological sciences).

For citation: Shekhovtsova E.S., Bulygina V.G. Regulation features in individuals with personality disorders and accentuated personality traits who committed aggressive and violent crimes. Penitentiary Science, 2020 , vol. 14 , no. 4 (52), pp. 581-588. DOI 10.46741/2686-9764-2020-14-4-581-588.

Assessing the extent of behavioral dysregulation in persons with borderline forms of mental disorders is a topical issue in legal psychol- ogy and penitentiary science. This is due to the necessity to evaluate self-regulation disorders in the framework of forensic psychiatric exami- 
nations and psychological assessments. Moreover, it is relevant in individualization of punishment and prevention of recidivism.

The importance of expert opinion on regulation disorders in persons who committed an offence is reflected in the Criminal Code of the Russian Federation. Thus, the extent of selfcontrol deficiency can influence the exemption of an individual from criminal liability (Part 3 of Article 20 of the RF Criminal Code, Article 21 of the RF Criminal Code) or be taken into account by the court when imposing a sentence (Article 22 of the RF Criminal Code). We should point out that these articles from the RF Criminal Code contain strict criteria such as the observance of the medical factor(presence or absence of a mental disorder); and Part 3 of Article 20 of the RF Criminal Code contains, among other things, the age factor. Thus, if adult defendants have borderline forms of mental disorders, we say they have full or "limited" sanity; the possibility of applying Article 22 of the RF Criminal Code is discussed in relation to individuals with borderline forms of mental disorder such as personality disorders if such individuals have pronounced motivational, analytical, foreseeing, and volition disorders, infantilism, etc. [2; 4; 6].

When addressing applied tasks of penitentiary science, the combination of borderline forms of mental disorders and limited sanity assumes major importance, because this very category of offenders is in the focus of attention of criminal psychiatrists due to the possibility of imposing forced medical treatment on such offenders.

According to Federal Penitentiary Service (FSIN) statistics for the years 2015-2018, correctional facilities held about $20 \%$ of individuals with those mental disorders that do not preclude legal sanity. According to B.A. Spasennikov, $36 \%$ of prison inmates have antisocial personality disorder, 24\% - emotionally unstable personality disorder, $10 \%$ - paranoid personality disorder [9]. The proportion of individuals with personality disorders is $15.8 \%$ among those who were ordered to undergo forensic psychiatric examination [5].

Despite the prevalence of this category of individuals in the penal system, the issues concerning comprehensive medical, psychological and social rehabilitation of convicts have not been given due attention so far.

According to FSIN data, in 2007-2019 the number of those convicted of more than a third offence increased by $5.4 \%$. The task of defining psychological features that are predictors of committing violent crimes is relevant from the scientific and practical perspective due to the increase in the number of repeat offences and pro- portion of violent crimes among individuals with personality disorders [2] and also due to the need for differentiated measures aimed to correct the behavior of convicts so as to prevent recidivism.

According to foreign researchers, there is a direct link between personality disorders and criminal behavior [12]. They also point out a high risk of committing aggressive and violent crimes by this category of individuals due to their specific personality orientation [11]. Russian psychiatrists and psychologists emphasize that personality disorder is a prerequisite for criminal behavior and pay special attention to motivation for a criminal act, the ratio between intact and broken links in the self-regulation chain, emotional, volition and motivational disorders. They highlight the spontaneity in developing an intention to commit a crime in a concrete situation [3; 7], the extent of influence of contextual factors on criminal aggression [8].

Thus, specific features of self-regulation system and situational analysis are major psychological variables that reflect the specifics of activity and the ability to regulate one's behavior consciously. Moreover, these variables can serve as targets for the work to prevent recidivism.

If a defendant possesses accentuated personality traits, then the question about their ability to understand the nature and public danger of their actions and control them has a definite answer, because accentuation of personality traits is not included in the list of mental diseases, i.e. the medical criterion of legally significant concepts is not met. However, personality accentuation is consistent with the concept of "locus minoris resistentiae" ("place of least resistance"), there exists a connection with an increased risk of maladjustment in certain situations due to sensitivity to some stress factors and simultaneous resistance to others.

Accentuation is an extreme variant of the norm, but it is not a criminogenic factor; nevertheless, it bears a risk of social maladjustment. Thus, accentuation has a significant impact on the socio-psychological adaptation of an individual, particularities of interpersonal relationships, ability to resolve conflict situations, behavior in frustration situations, risk of aggression and decrease in control over one's behavior. There are no fewer than $42 \%$ of individuals with various types of accentuated personality traits among convicts [10], the majority of them show pronounced hyperthymic and emotive traits $[1 ; 10]$. In the sample of individuals with criminal history most of those with accentuated personality traits were convicted of murder (56.8\%) and voluntary infliction of grievous bodily harm that entailed death (53\%). 
Thus, current state of the problem actualizes the need for substantiation of the data on regulation disorders taking into account the nature of committed offences so as to enhance the validity of expert conclusions, promote individualization in punishment, and build models for secondary psychological prevention.

The survey covered 134 men convicted of unlawful acts, including 94 individuals with personality disorders (PD), 20 individuals without mental disorders (MD) and 20 individuals with accentuated personality traits (APT). A control group was comprised of 20 surveyed individuals who were found mentally sane (MS). The expert commissions at Serbsky National Medical Research Center for Psychiatry and Narcology under the RF Ministry of Health found MS individuals and those with APT able to recognize actual nature and public danger of their actions and be in control of them. Regulation disorders that impede the ability to recognize and control one's actions were found in $21.3 \%$ of the surveyed. Table 1 shows the distribution of the surveyed according to the nature of offences they committed.

Table 1 - Distribution of the surveyed according to their nosologic classification, extent of behavioral dysregulation and the nature of delicts

\begin{tabular}{|c|l|c|c|}
\hline \multirow{2}{*}{ Diagnosis } & \multirow{2}{*}{ Decision of the expert commission } & \multicolumn{2}{|c|}{ Nature of the delict } \\
\cline { 3 - 4 } & & Aggressive and violent & Non-aggressive \\
\hline \multirow{3}{*}{ PD } & Sanity & $48.1 \%$ & $30.6 \%$ \\
\cline { 2 - 4 } & Limited sanity & $11.5 \%$ & $9.8 \%$ \\
\cline { 2 - 4 } & Total & $59.6 \%$ & $40.4 \%$ \\
\hline APT & Sanity & $55.0 \%$ & $45.0 \%$ \\
\hline MS & Sanity & $65.0 \%$ & $35.0 \%$ \\
\hline
\end{tabular}

The group of individuals who committed aggressive and violent crimes includes the surveyed who committed offences provided for in the following articles of the RF Criminal Code: Article 105 (murder), Article 111 (intentional infliction of grievous bodily harm), Article 119 (threat of murder or infliction of grievous bodily harm), Article 206 (hostage-taking). This group also includes acquisitive offences relating to the use of or the threat to use violence, namely, robbery (Article 161), assault with intent to rob (Article 162).

The group of persons who committed non-violent offenses includes the surveyed individuals who committed offences provided for in the following articles of the RF Criminal Code: Article 158 (theft), Article 159 (fraud), Article 228 (illegal acquisition, production, storage, and sale of narcotic substances), Article 128.1 (slander), Article 272 (illegal access to computer information), Article 222 (illegal acquisition, transfer, sale, storage, transportation or bearing of firearms, its basic parts, ammunition), Article 322 (illegal crossing of the state border of the Russian Federation).

To achieve our goal, namely, to allocate variables that are important for determining the ability to control one's actions, we developed the following methodological complex.

We used J. Kagan's Matching Familiar Figures Test (Kagan J., 1966) to assess reflexivity/ impulsivity in a situation of intellectual control. The test helps determine the extent of analysis of the situation and the time needed to make a decision, which is an important indicator in case a criminal situation emerges.
Besides, we used a semi-projective technique called "Situation analysis" (V.G. Bulygina, E.S. Shekhovtsova, A.A. Dubinskii, 2018). It is designed to assess analytical and forecasting opportunities depending on the situational environment (excess/lack of informational and emotional components for the analysis, level of uncertainty, degree of inconsistency of information); this can be the basis for allocating situations the regulation of which can be potentially dangerous.

"A new questionnaire for tolerance toward uncertainty" (T.V. Kornilova, 2009) was used to assess the ability to function in conditions of insufficient information. The questionnaire reveals the intensity of manifestation of tolerance/intolerance toward uncertainty, in interpersonal relationships as well.

We used J. Stroop's Color and Word Test (J.R. Stroop) to assess the ability to adjust one's behavior under the influence of interfering factors. The technique was used to assess general rigidity/flexibility of cognitive control; this trait performs a major role in the activity of an individual and influences their regulation abilities.

We determined the structure of self-regulation and the degree of awareness of its links with the use of a questionnaire "Behavioral selfregulation style" (V.I. Morosyanova, 1998). We assessed components such as planning, modeling, programming, assessment of results, flexibility, independence.

Statistical processing of the data was carried out with the use of descriptive statistics method and frequency analysis, an independent samples t- 
test, the Mann - Whitney U-test, and the Kruskal Wallis test to compare three independent samples.

At the first stage of our research we conducted comparative analysis of regulation features in the groups of individuals with personality disorders and accentuated personality traits, who had committed violent offences (fig. 1).

We found out that persons with PDs and APTs who had committed violent offenses are less tolerant toward uncertainty (TU), while intolerance toward uncertainty (ITU), in interpersonal association as well, is more pronounced in persons with PDs $(p<0.05)$. Thus, we can conclude that people with PDs in situations of increased uncertainty tend to use their routine behavior strategies, and their behavior in interpersonal relationships is characterized by instability and desire for control.

In cognitively complex conditions, all the examined individuals who committed aggressive and violent offenses show an insufficient degree of analysis of the situation; this leads to a predominance of erroneous responses $(p<0.001)$. At the same time, we note that individuals with PDs and APTs spend significantly less time analyzing the situation, which may indicate the predominance of impulsive behavior in a cognitively complex environment.

Cognitive control in individuals with PDs and APTs who committed aggressive and violent offenses is characterized by pronounced rigidity $(p<0.05)$, i.e. such individuals show a low degree of automation of verbal and sensoryperceptual functions, and, consequently, experience difficulties in switching between them. Accordingly, in contrast to other nosological groups of persons who committed aggressive and violent offenses, individuals with PDs and APTs have difficulties inadjusting their behavior, creating new behavioral strategies in a situation that objectively requires their revision.

Individuals with personality disorders are characterized by insufficient development of the regulatory system in general $(p<0.001)$, as well as its components such as planning $(p<0.001)$, modeling $(p<0.001)$, programming $(p<0.001)$ and evaluation of results $(p<0.001)$. Accordingly, we can say that individuals with PDs have a high risk of regulation disorders associated with insufficiency in goal setting, low feasibility of the plans they make, difficulties in thinking through the sequence of actions, inadequate assessment of significant internal conditions and external circumstances, their actions and results. Regulating and managing their behaviorin individuals with APTsis developed sufficiently, i. e. they are able to think through the ways of their actions and behavior to achieve their goals.

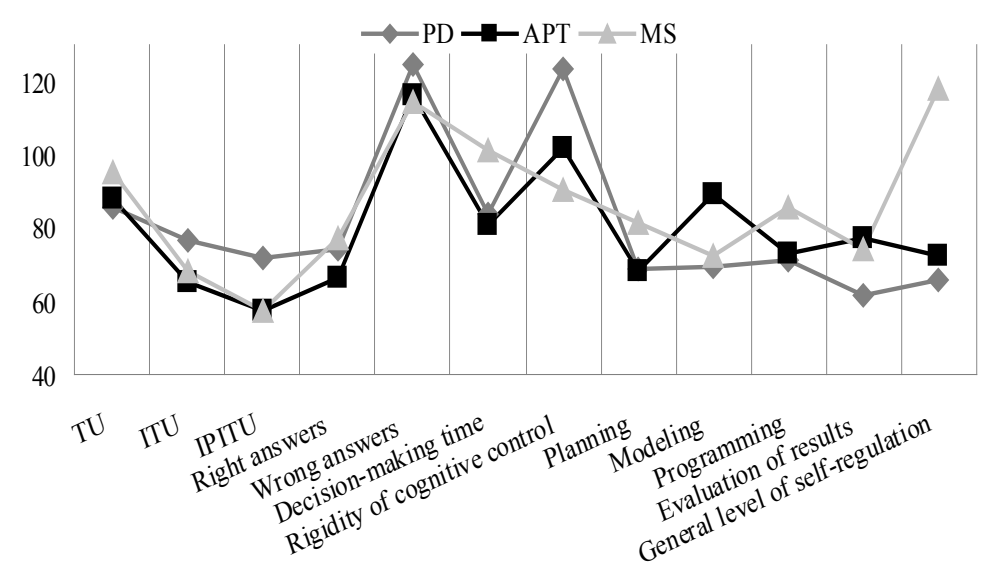

Figure 1 - Self-regulation indicators in the groups of surveyed individuals with PDs, APTs, and MS individuals who committed aggressive and violent offenses

The following features of situational analysis are specific for individuals with PDs and APTs who have committed aggressive and violent offenses. In a situation of information shortage, individuals with PDsshow poorly developed analytical ability, which is expressed in an insufficiently comprehensive and detailed perception of the situation. In the presence of perceptual interference and in the case of contradictory information, situational analysis in individuals with personality disorders is characterized by a low level of adequacy of interpretation of the situa- tion; moreover, in these conditions and with an increased emotional intensity of the situation, such individuals show an insufficiently developed ability to recognize the emotional states of other people (tab. 2).

In conditions of information deficit, individuals with APTsshow more developed analytical and forecasting abilities (compared to the group of individuals with PDs; however, their forecasting ability is developed insufficiently in comparison with both the group of individuals with PDs and the group of MS individuals (tab. 2) 
Table 2 - Significant differences in the variables of the situational analysis of examined individuals with PDs, APTs and mentally sane (MS) individuals who committed violent offenses (information shortage)

\begin{tabular}{|l|c|c|c|c|}
\hline \multicolumn{1}{|c|}{ Variable } & PD & APT & MS & \multirow{2}{*}{ Pverage rank } \\
\cline { 2 - 5 } & \multicolumn{3}{|c|}{ P } \\
\hline Completeness of description of the situation & 31.15 & 41.96 & 49.96 & 0.004 \\
\hline Extent of detailed elaboration in the description of the situation & 30.90 & 42.38 & 50.42 & 0.002 \\
\hline Number of alternatives for further development of the situation & 33.15 & 31.50 & 34.27 & 0.010 \\
\hline Presence of perceptual interference & 33.39 & 42.00 & 42.00 & 0.027 \\
\hline Adequacy of interpretation of the situation & 33.20 & 36.04 & 48.65 & 0.035 \\
\hline Recognizing the emotions ofparticipants in the situation & \multicolumn{4}{|c|}{} \\
\hline Controversial situation & 33.69 & 41.50 & 41.50 & 0.040 \\
\hline Adequacy of interpretation of the situation & 32.01 & 42.12 & 46.77 & 0.024 \\
\hline Recognizing the emotions of participants in the situation & 32.07 & 41.04 & 47.65 & 0.020 \\
\hline
\end{tabular}

If information in the situation is sufficient, then individuals with PDsshow an insufficiently developed ability to recognize the emotional component of a situation, in contradictory situ-

ations as well. Individuals with APTsshow an insufficient level of development of forecasting ability, in the presence of perceptual interference as well (tab. 3).

Table 3 - Significant differences in the variables of the situational analysis forsurveyed individuals with $P D$ s, APTs and mentally sane (MS) individuals who committed violent offenses(information sufficiency)

\begin{tabular}{|c|c|c|c|c|}
\hline \multirow{2}{*}{ Variable } & PD & APT & MS & \multirow{2}{*}{$\mathbf{P}$} \\
\hline & \multicolumn{3}{|c|}{ Average rank } & \\
\hline Recognizing the emotions of participants & 32.39 & 41.50 & 46.04 & 0.042 \\
\hline \multicolumn{5}{|l|}{ Presence of perceptual interference } \\
\hline Number of alternatives for further development of the situation & 36.39 & 27.69 & 45.69 & 0.036 \\
\hline \multicolumn{4}{|l|}{ Controversial situation } & \\
\hline Number of alternatives for further development of the situation & 34.11 & 33.65 & 47.81 & 0.017 \\
\hline Recognizing the emotions of participants in the situation & 31.72 & 42.65 & 47.27 & 0.015 \\
\hline
\end{tabular}

At the next stage, we performed a comparative analysis (Student's t-test) of regulation features for each group of individuals with PDs and APTs. Comparison groups included surveyed idividuals of the same nosological group who committed non-aggressive offenses. The main task of this stage was to identify specific regulation features within a single nosological group.

Thus, we found that individuals with PDs have a less developed propensity to plan their ac- tivity $(p<0.05)$ and change their behavior in a changing environment $(p<0.05)$ (fig. 2). Thus, we can say that persons with PDs who have committed aggressive and violent offenses have a tendency to set goals judging by the situation;moreover, they are unable to respond adequately to the situation and regulate their behavior in a dynamic and rapidly changing environment.

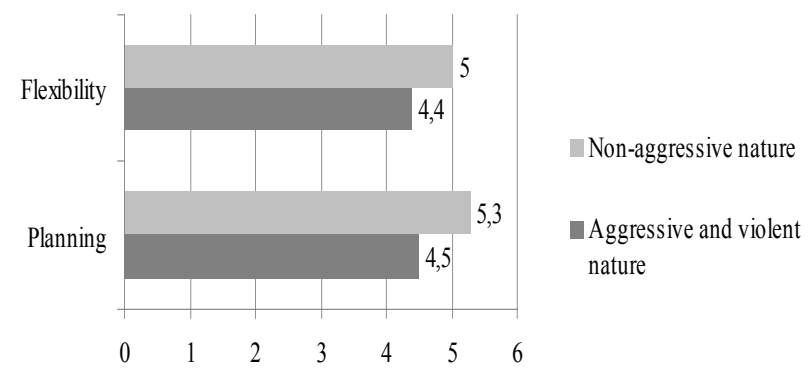

Figure 2 - Graph of average values of self-regulation indicators in groups of surveyed individuals with PDs, depending on the nature of offence

In a situation of information shortage, pressed in the presence of a variety of adforecasting abilities in individuals with PDs equate alternatives $(p<0.01)$ when making who committed aggressive and violent of- a forecast of how the situation will develop fences are more pronounced, which is ex- (fig. 3). 

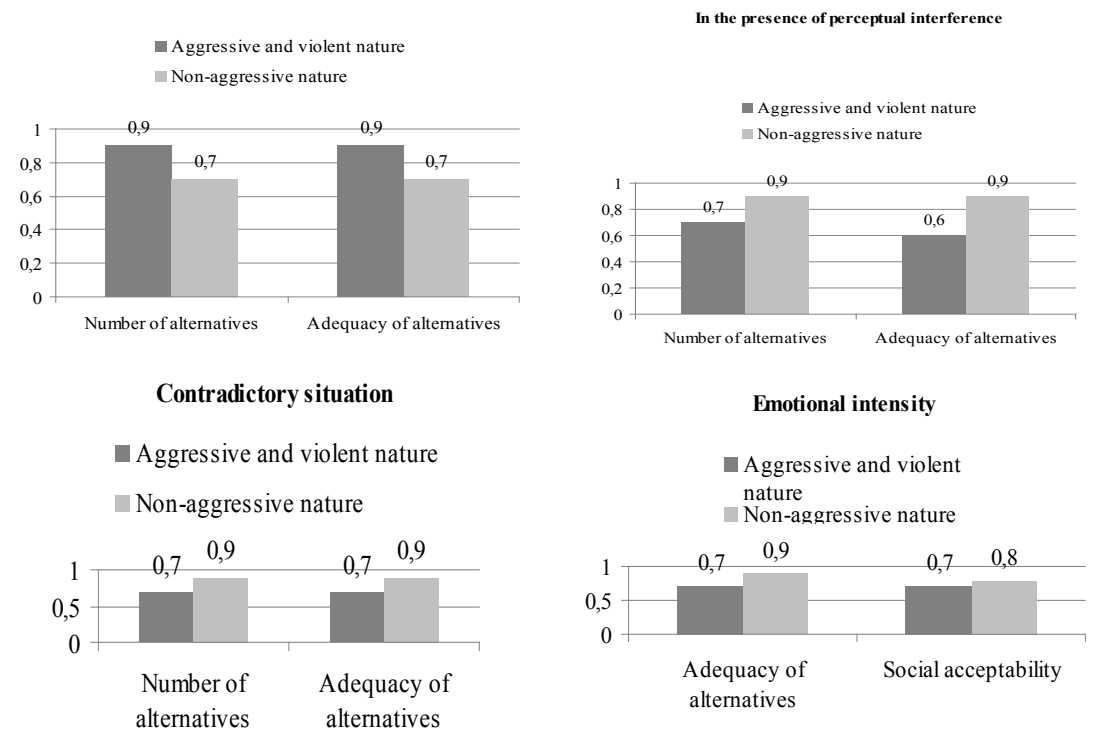

Figure 3 - Graphs of average values of situational analysis indicators in conditions of information shortage for individuals with PDs, depending on the nature of offense

At the same time, when the situation becomes more complex in terms of information or emotions, individuals with PDs in this group are less likely to predict the consequences correctly $(p<0.001)$. Also, in an emotionally intense situation,persons who committed aggressive and violent offenses put forward alternatives that lack social orientation $(p<0.05)$.

Thus, in individuals with PDs who committed aggressive and violent offenses, the risks of behavioral dysregulation associated with the ability to predict the consequences of the situation adequately and offer socially acceptable alternatives to resolve the problem situation under information shortage increase when the en- vironment becomes more complex, when the situation contains contradictory information, perceptual interference, or if the emotional intensity of the situation is excessive.

In conditions of information sufficiency, individuals with PDs who committed aggressive and violent crimes put forward alternatives that are less acceptable from the social perspective $(p<0.05)$, this happens in the presence of perceptual interference $(p<0.01)$ and in an emotionally intense situation as well $(p<0.05)$. Also, in cognitively complex and emotionally intense situations, such individuals fail to produce sufficiently adequate alternatives $(p<0.05)$ (fig. 4).
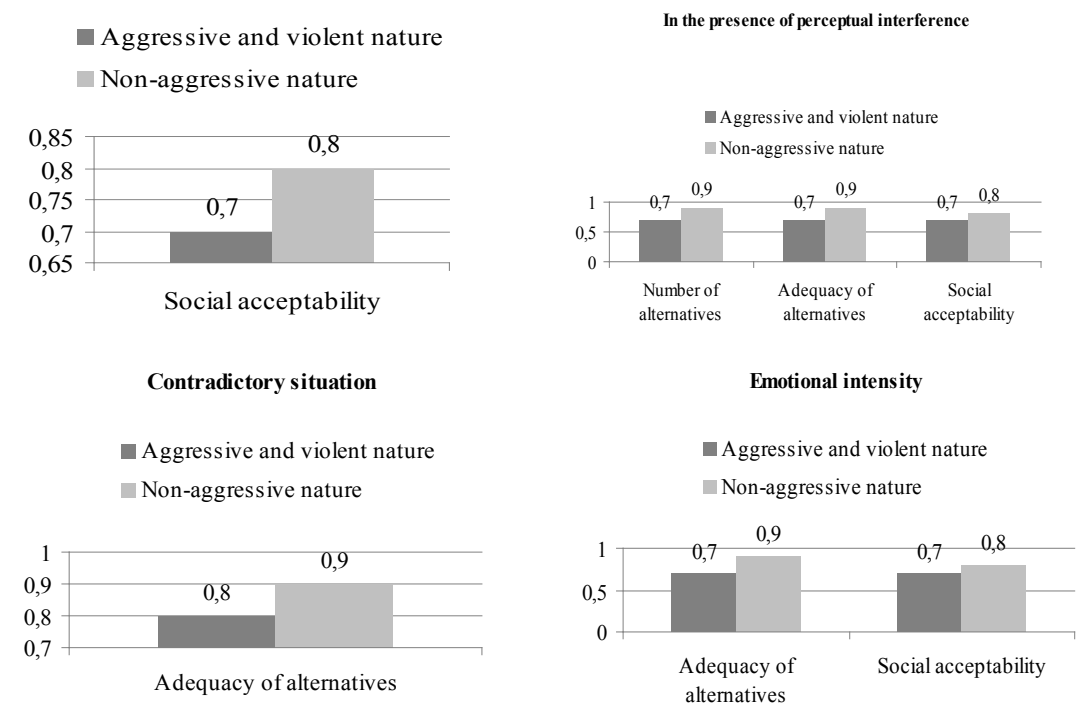

Figure 4 - Graphs of average values of situational analysis indicators in conditions of information sufficiency for individuals with PDs, depending on the nature of offense 
Thus, in a situation in which theamount of information is sufficient, regulatory disorders in individuals with PDs who have committed aggressive and violent offenses are manifested in difficulties in making an adequate forecast of the situation, assessing the consequences of choosing a particular behavior strategy, and taking into account social norms when making a decision.
We found that individuals with APTs significantly differ only in the situational analysis parameter. Thus, when information is insufficient in the context of contradictory information or emotional intensity, individuals convicted of aggressive and violent offenses are less likely to analyze the emotional component of the situation $(p<0.05)$ (fig. 5).

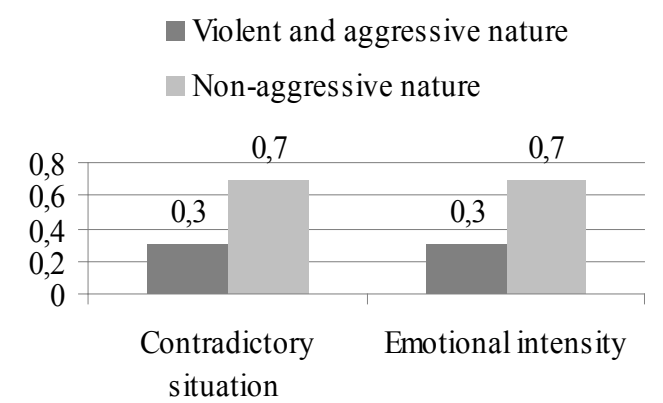

Figure 5 - Graph of average values of the ability to take into account the emotional context of the situation in conditions of information deficit in individuals with APTs, depending on the nature of offense

Under information redundancy, individuals with PDs accused of committing aggressive and violent offenses also experience difficulties forecasting the situation adequately $(p<0.05)$; they produce a small number of socially acceptable alternatives $(p<0.05)$, including under information $(p<0.05)$ or emotional intensity $(p<0.05)$. At the same time, they put forward a greater number of aggressive alternatives $(p<0.01)$ (fig. 6).
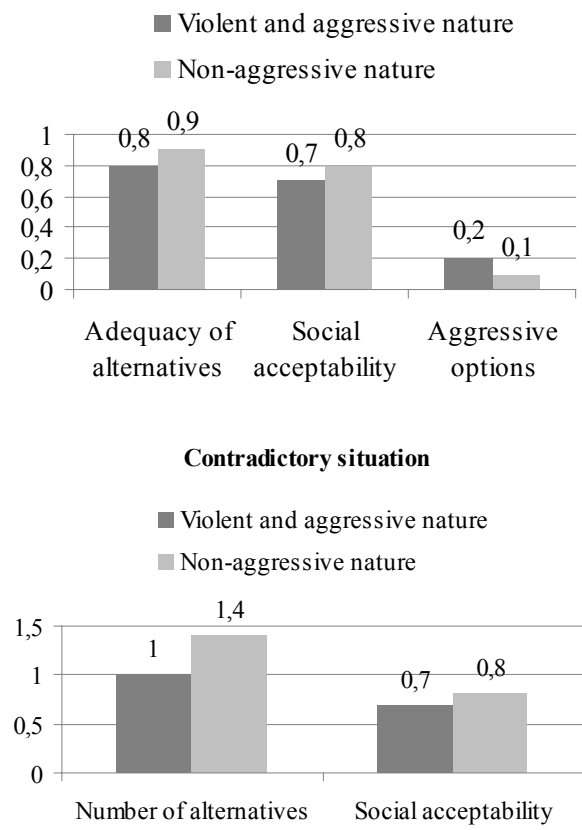

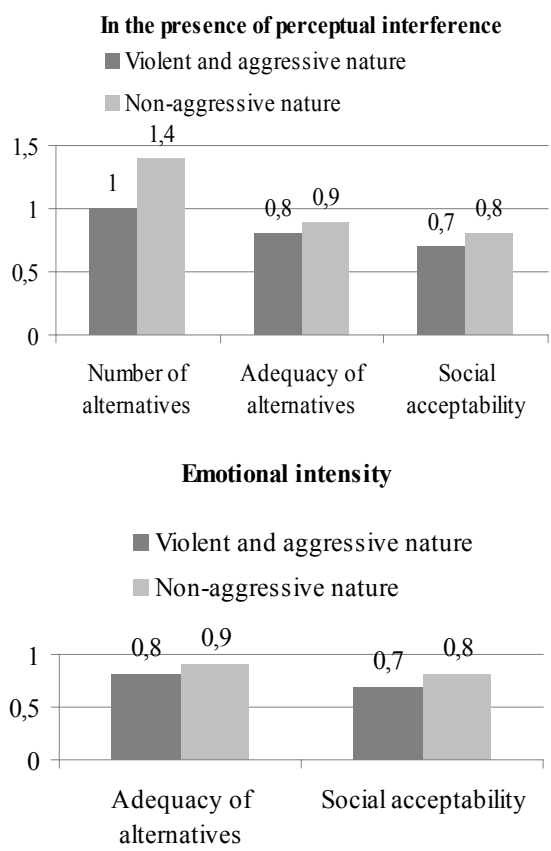

Figure 6 - Graphs of average values of indicators of situational analysis in conditions of information redundancy in individuals with PDs, depending on the nature of offense

Thus, in conditions of information redundancy, individuals with PDs who have committed aggressive and violent offences, not only have difficulties in providing an adequate forecast of future development of the situation; they also have higher risks of responding in aggressive forms with a low rate of social orientation of their forecast.

The research we conducted with the help of modeling decision-making situations has al- 
lowed us to identifyfeatures specific to individuals with personality disorders who committed aggressive and violent offenses. We have found that behavioral dysregulation is associated with the ability to predict the consequences adequately and offer socially acceptable alternatives to resolve a problem situation.In situations of information deficit, contradictory information, in the presence of perceptual interference or increased emotional intensity of the situa- tion, the probability of violation of conscious regulation of behavior increases significantly.

Thus, we consider it relevant to draw on the indicators revealed in the framework of the present research, since they can be of use inaddressing certain tasks of penitentiary science and practice. The indicators can be predictors of behavioral dysregulation and aggressive response and also serve as targets for psychological treatment.

\section{REFERENCES}

1. Alekseeva T.V. Characterological features of the personality of convicts. Byulleten' meditsinskikh internet-konferentsii = Bulletin of Online Medical Conferences, 2014, vol. 4, no. 3, p. 136. (In Russ.)

2. Gorinov V.V. Personality disorders: modern classifications, diagnostics and features of expert assessment. In: Vandysh V.V. (Ed.) Sudebnaya psikhiatriya. Aktual'nye problemy [Forensic psychiatry. Topical issues]. Moscow: FGBU "NMITs PN im. V.P. Serbskogo" Minzdrava Rossii, 2018. Issue 15. Pp. 50-63. (In Russ.).

3. Kudryavtsev I.A., Lapshina E.N. Psychological mechanisms and effects of character pathology influence on selfregulation of socially dangerous actions. Rossiiskii psikhiatricheskii zhurnal = Russian Journal of Psychiatry, 2008, no. 3, pp. 29-35. (In Russ.).

4. Lapshina E.N. Osobennosti samoregulyatsii lits, priznannykh ogranichenno vmenyaemymi: dis. ... kand. psikhol. nauk [Features of self-regulation of individuals found partially sane: Candidate of Sciences (Psychology) dissertation]. Moscow: FGU "GNTsSSP im. V.P. Serbskogo", 2006. 265 p.

5. Makushkin E.V., Mokhon'ko A.R., Mugantseva L.A. Forensic psychiatric expert service of the Russian Federation in 2018 (based on the materials of the industry statistical reporting of the Ministry of Health of Russia). Psikhicheskoe zdorov'e = Mental Health, 2019, no. 7, pp. 3-15. (In Russ.).

6. Savina O.F., Makushkin E.V., Morozova M.V. The algorithm of forensic expert study of the dysregulation of activity in criminal situation in persons with mental disorders. Rossiiskii psikhiatricheskii zhurnal = Russian Journal of Psychiatry, 2018, no. 1, pp. 31-42. (In Russ.).

7. Safuanov F.S. Psikhologiya kriminal'noi agressii [Psychology of criminal aggression]. Moscow: Smysl, 2003. 300 p.

8. Safuanov F.S., Kalashnikova A.S., Tsar'kov A.E. Clinical and psychological drivers of criminal aggression. Psikhologiya $i$ pravo = Psychology and Law, 2017, vol. 7, no. 4, pp. 44-58. doi10.17759/psylaw.2017070405. (In Russ.).

9. Spasennikov B.A. Clinical criminologic analysis of personality disorders of the convicted.Kriminologicheskii zhurnal Baikal'skogo gosudarstvennogo universiteta ekonomiki i prava = Criminology Journal of Baikal National University of Economics and Law, 2014, no. 2, pp. 33-40. (In Russ.).

10. Steshich E.S. Character accentuations and criminal behavior (according to the study of prisoners convicted of intentional killing or reckless killing). Psikhopedagogika $v$ pravookhranitel'nykh organakh = Psychopedagogy in Law Enforcement, 2018, no. 1 (72), pp. 29-35. (In Russ.).

11. Hare R.D., Neumann C.S. Psychopathy: assessment and forensic implications. Canadian Journal of Psychiatry, 2009, vol. 54, pp. 791-802.

12. Skeem J.L., Cooke D.J. Is criminal behavior a central component of psychopathy? Conceptual directions for resolving the debate. Psychological Assessment, 2010, vol. 22 (2), pp. 433-445.

\section{INFORMATION ABOUT THE AUTHORS}

ELENA S. SHEKHOVTSOVA - Researcher at the Department of Psychogenic Diseases and Personality Disorders, Serbsky National Medical Research Center for Psychiatry and Narcology under the Ministry of Health of the Russian Federation. ORCID: https://orcid.org/0000-0003-3379-3521, e-mail: shiha.|@mail.ru

VERA G. BULYGINA - Doctor of Sciences (Psychology), Head of the Laboratory for Mental Hygiene and Psychophylaxis, Serbsky National Medical Research Center for Psychiatry and Narcology under the Ministry of Health of the Russian Federation; Professor at the Department of Clinical and Forensic Psychology, Moscow State University of Psychology \& Education, Moscow, Russian Federation. ORCID: https://orcid.org/0000-0001-5584-1251, e-mail: ver210@yandex.ru 